\title{
Impact of Management Information Systems (MIS) on Decision Making
}

\author{
Md. Monsur Ali
}

Assistant Professor, Department of Business Administration, Dhaka City College, Dhaka - 1205, BANGLADESH

Corresponding Contact:

Email: alimd.monsur@yahoo.com

Manuscript Received: 18 July 2019 - $\quad$ Revised: 08 Sept $2019 \quad$ - $\quad$ Accepted: 26 Sept 2019

\begin{abstract}
Today's business environment is unpredictable, dynamic, unstable and, necessitates the growing demand for accurate, relevant, complete, timely and, economical information needed to drive the decision-making process. The quick developments of information technology coupled with the development of telecommunications technologies, have modernized all areas of business and human activities. In today's business world, there are different types of information systems. Each plays a unique role for a manager decision-making functions. In this paper, the decision maker's satisfaction, contents of information and information access quality have been analyzed and studied. Here identified necessary variables aiming to evaluate the influence of management information systems in decision support capabilities and side by side discuss the concept, characteristics, types of MIS, the MIS model, and in particular it will highlight the impact of MIS in decision making. At the same time, different models and figures are presented to enrich the discussion and to highlight the status of each MIS and DSS information systems in an organization decision-making process.
\end{abstract}

Key Words: MIS, Database, Information access, Decision support system, Decision quality, Decision-making process, organization

\section{INTRODUCTION}

The information system is an integrated set of components for collecting, storing, and processing data and for delivering information, cards, and digital products. Business firms and other organizations rely on information systems to carry out and manage their operations, interact with their customers and suppliers, and compete in the marketplace. Management Information System is flow-processing procedures based on computer data and linked with other procedures to provide information in a timely and effective manner to support decision-making and other managerial functions. Computer system processor often defined as inputs to outputs or information. The information system define as a set of related elements with attributes that enable their electronic data processing (Mustafa Muhamet, 1995). Firms utilize innovation to obtain advantages that indirectly or directly impact economic performance indicators (Cagwin and Bouwman, 2002). 
Computers use in all areas in business. In most cases viewed as information system consist of people, equipment and procedures to collect, arrange, analyzed, assessed and disseminated timely information to decision receiver or as a formalized computer system that can collect, feed, process, and report data from various sources to provide the necessary information for management decision-making processes (James O. Hicks Jr., 2003). For the last few decades, different kinds of information systems have developed for various purposes, depending on the needs of the business. In today's business world, there are varieties of information systems such as TPS, DAS, KWS, MIS, DSS, ES, CSCWS, GDSS and ESS. Each plays diverse roles in organizational hierarchy, decision making, and taking processes.

\section{Management Information Systems (MIS)}

The Management Information Systems (MIS) is comparatively a new concept which involves decision making and taking of a manager in the competitive business world. It understand and describe in several ways. It is also known as the Information System, the Information and Decision System, the Computer-based information System (Davis \& Geist, 2004). In other word, MIS defines as a system which provides information support for decision making in the organization. The MIS defines as an integrated system of man and machine for providing the information to support the operations, the management and the decision making function in the organization. The MIS is defined as a system based on the database of the organization evolved to provide information to the people in the organization. The MIS defines as a computer-based information system. The information system is entirely related elements among themselves, which function together for collecting, processing, and saving of information distribution. The information system a formalized computer system that collects, stores, processes, and reports data from various sources to provide information needed to managers (O. Hicks, 2003). Computer operating systems mentioned five tasks or activities: data collection; data processing; data management; control and security of data and information generation. Through these activities, data from various sources through a process called data processing to turn into useful information for the user. Management information systems comprise the physical components of the trailer: hardware, software, databases, procedures, and personnel. The computing system is formalized system were collected and sorted out by several processes, reports, data from various sources to provide the necessary information and important to obtain management decisions (James O. Hicks Jr., 2003). The purpose of the system is processing information, the saving and transmitting appropriate information in place, and better information system is the one who performs this function with much less expense, Fig. 1 reflects computer system in six parts: inputs, processes, data files, outputs, personnel, and hardware part. The process of transforming inputs into outputs regards to information management (management information). Processes subdivide into computer programs, and procedures, computer programs executed from the hardware and procedures accomplish by humans.

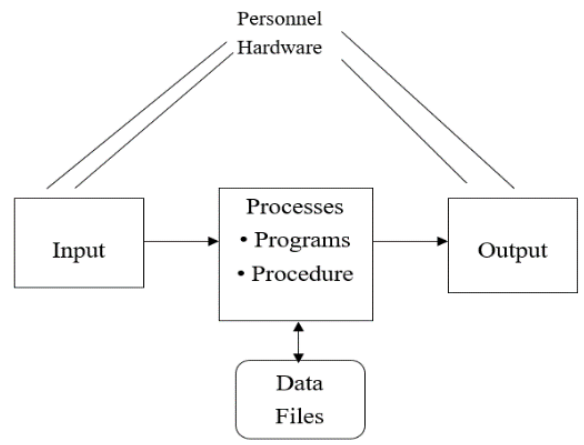

Figure 1: Computer System 
Figure 1 Shows that the introduction of the computer system before the 1980s when the information system was classified as a system for data processing or computing system governing. System data processing was oriented toward conquest, processing, booking (storage) data, while MIS directs towards utilization of data to create information governance.

Today the term generally refers to the system that provides periodic information on events familiar and predictable business (James O. Hicks, Jr. 2003). The main functions that make up the essence of management as a process in the contemporary organization are planning, organizing, staffing, leading, and controlling. Since managers are responsible for setting goals, they have to make decisions that enable their achievement, and those decisions relating to activities as following:

- $\quad$ To prepare the of strategic goal;

- Manage the implementation of strategic decisions;

- To organize different activities;

- Defining the tasks and resources associated with the appearance of their uses;

- Coordination and supervision of employees and managers;

- Detection and correction of problems if they occur.

\section{Objectives of the Study}

The main objective of the study is to examine the impact of management information systems on effective decision making. In light of identifying the problem and its importance, the objectives determine according to the following ways:

- To decide the troubles associated with Management Information Systems (MIS).

- To find out how MIS influence the decision-making process.

- To identify the benefits of MIS to motivate the employees.

- To determine the role played by MIS in the achievement of organizational goals.

- Make out the nature of the relationship between management information systems and managerial decision-making.

- To reach some conclusions and suggestions that will contribute to increasing the efficiency of information systems in the effectiveness of the managerial decision-making process.

\section{Components of MANAgement InFORMATION SyStems (MIS)}

To effectively deliver the information needed to decision-makers, Management Information Systems need to have the necessary components to collect, process, store, and retrieve the information whenever it is needed (Digman and Lester, 1990) have clarified that the rare resource today is not the availability of information, but the ability to process that information. To achieve these systems use the following four components:

Information System: This is a combination of software, hardware, personnel, and infrastructure. This component helps in the collection of data that store in the MIS. The hardware includes computers, scanners, printers, and network devices. The software elements include the company's enterprise software and any other software that is used in the running of the company's network. This component makes it possible for employees to interact with the system and thus information can collect.

Database Management System: This component is primarily made up of computer programs that help in the storage and retrieval of data. Of course, it also includes the actual physical databases where the information store after it capture. There are several database 
management systems that can use in MIS. The suitability of the systems will depend on the amount of data that will need to process and store in the system.

Intelligence System: This component is concerned with the processing of the data collected and presenting it in a manner that is easy to grasp. Everything from the processing of the data to the displaying of the data design to give top executives an easy time as they try to make decisions concerning the business. It sometimes refer to as business intelligence, which stores human knowledge and uses the logic to formulate quick solutions for future problems where patterns match.

Research System: This component is concerned with identifying the management problems in the organization and coming up with alternative decisions that could have sufficed in a particular situation. It helps ensure that all the possible options are analyzed and the best decision made. The decision is not always the most obvious one. This component of Management Information Systems ensures that the decision is reached even in those instances.

\section{TYPES OF INFORMATION SYSTEMS}

In any organization, information systems can classify based on the usage of the information. Management Information Systems is one of several information systems that are used in businesses today. To better understand Management Information Systems; let's see the different types of information systems are available:

- Transaction Processing Systems. These systems have designed to collect, process, and store transactions that occur in the day to day transaction across departments of an organization. The system can also be used to cancel or modify transactions done in the past if the need arises. One property of this system that enables them to work effectively is the ability to accurately record multiple transactions even if the different transactions take place simultaneously. They are built to be able to handle large volumes of transactions. Examples include stock control systems, payroll systems, order processing systems, etc. These transactions can categorize into batch transaction processing, single transaction processing, and real time-transaction processing.

- Decision Support Systems: These systems help decision-makers to make the best decisions by generating statistical projections from analyzed data. Although it does not eliminate the need for the manager's judgment, it significantly improves the quality of the decision by offering forecasts that help determine the best course of action. These systems compile information from several sources for purposes of aiding in decision making. Examples of these systems include computer supported cooperative work, group decision support systems, logistics systems, and financial planning systems. The primary goal of DSS should be to enhance overall performance, but not to obtain more precise costs (Cooper and Kaplan, 1992).

- Executive Information Systems: Senior management uses an EIS to make decisions that affect the entire organization. Executives need high-level data with the ability to drill down as necessary. These systems provide quick and easy to use reports that present in graphical displays that are easy to compare. They can be taken as specialized decision support systems because they provide information necessary to help improve the quality of decisions. Owing to the high expectations from such a system, these systems need to be highly individualized; hence, they are usually custom made for specific clients. They are customizable to fit particular needs of the clients.

- Management Support System: Managers require precise information in a specific format to undertake an organizational decision. A system which facilitates an efficient decision-making process for managers call management support system. Management support systems categorize as management information system, decision support system, expert system, and accounting information system. 
- Operations Support System: In an organization, data input is done by the end-user who is processed to generate information products, i.e., reports, which are utilized by internal and or external users. Such a system is called operation support system. The purpose of the operation support system is to facilitate the business transaction, control production, support internal as well as external communication and update the organization central database. The operation support system further divide into a transaction-processing system, processing control system, and enterprise collaboration system.

- Process Control System: In a manufacturing organization, decisions are made by a computer system without any manual intervention. Here critical information is fed to the system on a real-time basis thereby, enabling process control. This kind of systems refer to as process control systems.

- Enterprise Collaboration System: In recent times, there is more stress on team effort or collaboration across different functional teams. A system which enables collaborative effort by improving communication and sharing of data refer to as an enterprise collaboration system.

- Customer Relationship Management System: A CRM system stores key information about customers, including previous sales, contact information, and sales opportunities. Marketing, customer service, sales, and business development teams often use CRM.

- Supply Chain Management System: Manufacturing companies use SCM to track the flow of resources, materials, and services from purchase until final products are shipped.

\section{ROLES OF MANAGEMENT INFORMATION SYSTEMS (MIS)}

Nowadays all the managerial functions are performed through decision-making. To take the right decision, timely and reliable information is essential and is procured through a logical and wellstructured method of information collecting, processing and disseminating to decision-makers. Today must have a properly planned, analyzed, designed, and maintained MIS so that it provides timely, reliable, and useful information to enable the management to take rational decisions.

- The MIS plays the role of information generation, communication, problem identification, and helps in the process of decision-making. The MIS, therefore, plays a vital role in the management, administration, and operation of an organization.

- It helps indirectly to pull the entire organization in one direction towards the corporate goals and objectives by providing the relevant information to the organization.

- Because of the liberalization and globalization, a manager has to take prompt decisions, MIS helps to take the quick decisions.

- Now information is doubling up every two or three years; a manager has to process a voluminous data, MIS cooperate to manage the data.

- The MIS helps in the clerical personnel in the transaction processing and answers the queries on the data about the transaction, the status of a particular record and reference on a variety of documents.

- The MIS helps the junior management personnel by providing the operational data for planning, scheduling, control, and helps them further in decision-making at the operation level to correct an out of control situation.

- The MIS helps the middle management in short term planning, target setting, and controlling the business functions.

- The MIS helps the top-level management in goal setting, strategic planning, and evolving the business plans and their implementation.

- The MIS satisfies the diverse needs through a variety of systems such as query system, analysis system, modeling system, and decision support system. 
- The MIS helps in strategic planning, management control, operational control, and transaction processing.

\section{IMPACT OF MIS}

A good MIS supports the management of marketing, finance, production, and personnel. The tracking and monitoring of the function targets become easy. The managers are informed about the progress, achievements, and shortfalls in the activity and the objectives. The manager is kept alert by providing certain information indicate the trends in the various aspects of a business.

The MIS creates another impact in the organization, which relates to the understanding of the business itself. It uses a dictionary of data, entity, and attributes, respectively, designed for information generation in the organization. Since all the information systems use the dictionary, there is a common understanding of terms and terminology in the organization, bringing clarity in the communication and a similar perceptive of an event in the organization.

The MIS calls for systematization of the business operations for effective system design. This leads to streaming of the function which complicates the system design. It improves the administration of the business by bringing a discipline in its operations as everybody is required to follow and use systems and procedures. This process convey a high degree of professionalism in a business operations.

A well-designed system with a focus on the manager makes an impact on managerial efficiency. It helps him to resort to such exercises as experimentation and modeling. The application of computers enables him to use the tools and techniques which are impossible to use manually. The ready-made packages make this task simple. It improves decision-making ability considerably high. Since, the MIS work on the system such as transaction processing and database, the drudgery of the clerical work is transferred to the computerized system, relieving the human mind for better job.

\section{Information Systems ANd MANAgerial Decision MAKING}

There is a direct link between behavior control, outcome control, clan control, self-control with firm performance, and with the moderating effect of the complexity risk (Kirsch, 1997). The relationship between information systems and decision making is very close. The availability of information in large quantities means power, provides organizational options, and an effective decision-maker can determine the best options at a tremendous speed, but sometimes the decision-maker cannot obtain information due to lack of availability or lack of access. Because the prices and the cost of collection are very high, the less information the ambiguity, and increased the degree of risk and the increased risk of non-decision. But after the adoption of the modern scientific method in management, the decision is no more made by intuition or guessing or even based on the experience of the manager, but depends on the exact search which could not be achieved except by collecting data on all aspects of the problem then analyzing, interpreting and translating it into reality to help making the decision.

The managerial decision is considered the substance of process and it means to achieve the objectives of the organization; the success of the organization depends on the management's effectiveness in decision making. The decision in its form is reaching a solution for a present problem or achieving planned objectives; the word decision means judging in an issue. MIS also changes the amount of data into the compiled form and thereby avoids the possible ambiguity that may arise when managers are swamped with detailed facts. (Ryals, 2005). From an administrative view one refers to decision as a selection between alternatives to solve 
a problem or to achieve an objective (Nawaf, 2003). Decision as to the perceived selection between the available options in a situation. Decision-making as the flexible process of choosing the appropriate alternative after examining all aspects of the problem within the available information taking into account the period and the cost to reach the maximum expected the benefit to achieve the desired goal (Al-Ajlouni, 1998). Generally decisions divided into two basic types: programmed and nonprogrammer decisions.

Programmed decisions are routine and repetitive decisions, and the organization typically develops specific ways to handle them. For this kind of routine cyclical decisions, standard arrangement decisions made according to established management guidelines.

Non-programmed decisions, in contrast, are typically one-shot decisions that are usually less structured than programmed.

\section{Steps of Managerial Decision-Making Process}

Making decisions consists of several activities. There are five stages of decision making:

- To identify and define the problem: The first step in decision making is to identify and define the problem. "This is a stage of information gathering, information processing, and deliberation. It is also where goals are clarified to specify what a decision should accomplish. The more specific the goals, the easier it is to evaluate results after implementing the decision.

- Search for and develop alternative solutions: After identifying the problem and its dimensions in the light of the information provided, one must be directed to the search for solutions and tests leading to the achievement of the goal, which is to be able to solve the problem in a timely manner and within the limits of the available physical resources.

- Evaluating the expected results of each alternative: This process determines the pros and cons of each alternative, i.e., identifying the advantages and disadvantages of each, and evaluating in light of the potential benefits achieved, compared with the costs, thus focusing on which give the greatest benefits.

- The choice of the best substitute: In light of the economic, social and environmental considerations on the one hand and the degree of knowledge of the decision-maker on the other hand, one of the alternatives will be selected based on the pros and cons.

- Implementation of the decision and follow-up: The decision making process does not end until the implementation. It ensures that the decision taken has already achieved a comprehensive solution to the problem. Through feedback information to ensure the integrity and the safety of implementing and to address any impediments to the accomplishment process as they arise which may require the cancellation of the decision or replacing it.

\section{CONCLUSION}

MIS is a concept linked with man, machine, marketing, and methods for collecting information from the internal and external sources and analyzing this information to facilitate the process of decision-making of the business. Management information systems are believed to foster the process of decision-making capabilities. The identification and analysis of problem facilitating the role management information systems not studied. Also a way to increase company operations and improve their effectiveness, organizations adopt new management techniques with the goal of enhancing decision-making processes, improve results, and finally reduce costs. (Henry, 2001; AlMaryani and Sadik, 2012). Although there are many benefits of integrating information technology in businesses, there some drawbacks when it comes to MIS (Liang et al., 2007). An implementation may also cause the elimination of jobs when people that were performing the tasks MIS performs now become obsolete (Pfeffer and Sutton, 2000). Information technology systems 
also become vulnerable to security breaches, via the internet (Gray, 2000). In the long run, a good, and most of all operational, functional, and efficient management information systems should be sustained by electronic data communication network systems that are proven to be stable and reliable. With the use of information systems, the exchange of information can be improved considerably and more efficiently (Priem and Butler, 2001). The success of information systems will enhance the performance of enterprises (DeLone and McLean, 2003).

\section{REFERENCES}

Al-Ajlouni, Mohamed A.F. (1998). Evaluation of Management Information Systems Applications in Selected Public and Private Corporations in Jordan, Master Thesis, Al-Bayt University, Jordan.

Al-Maryani, M. A. H., \& Sadik, H. H. (2012). Strategic Management Accounting Techniques in Romanian Companies: Some Survey Evidence. Procedia Economics and Finance, 3, 387-396.

Cagwin, D., \& Bouwman, M. J. (2002). The association between activity-based costing and improvement in financial performance. Management Accounting Research, 13(1), 1-39.

Cooper, R., \& Kaplan, R. S. (1992). Activity-based systems: Measuring the costs of resource usage. Accounting Horizons, 6(3), 1-13

Davis, F. D. (1989). Perceived usefulness, perceived ease of use, and user acceptance of information technology. MIS Quarterly, 13 (3), 319-340.

Delone, W. H., \& McLean, E. R. (2003). The DeLone and McLean model of information systems success: a ten-year update. Journal of management information systems, 19(4), 9-30.

Digman, L.A. (1990) Strategic Management: Concepts, Decision, Cases, 2nd (edn.), Richard D. Irwin. Inc Boston.

Gray, P. H. (2000). The effects of knowledge management systems on emergent teams: towards a research model. The journal of strategic information systems, 9(2), 175-191.

Henry, J. (Ed.). (2001). Creative management. Sage.

Kirsch, L. S. (1997). Portfolios of control modes and IS project management. Information Systems Research, 8(3), 215-239.

Liang, H., Saraf, N., Hu, Q., \& Xue, Y. (2007). Assimilation of enterprise systems: the effect of institutional pressures and the mediating role of top management. MIS quarterly, 59-87.

Mohammed A, and $\mathrm{Hu}, \mathrm{W}$ (2015) Using Management Information Systems (MIS) to Boost Corporate Performance International Journal of Management Science and Business Administration, 11(1), p 55 - 61

Nawaf, K. (2003). Administrative Decision Making between Theory and Practice, First (edn.), Dar Wael Publishing and Distribution, Amman.

O'Brien, James A., Introduction to Management Information Systems: Essentials for the e-business enterprise, 11th ed., McGraw-Hill Companies, Inc., Irwin, 2003.

Pfeffer, J., \& Sutton R. I. (2000). The knowing-doing gap.

Priem, R. L., \& Butler, J. E. (2001). Is the resource-based "view" a useful perspective for strategic management research?. Academy of management review, 26(1), 22-40.

Ryals, L. (2005). Making customer relationship management work: the measurement and profitable management of customer relationships. Journal of Marketing, 69(4), 252-261.

Sadiq U. Khan A.F. khlaqk K, Mujtaba B.G. (2012). The Impact of Information Systems on the Performance of Human Resources Department, Journal of Business Studies Quarterly, 3(4): 77-91,

Tomlinson, P. R. (2010). Co-operative ties and innovation: Some new evidence for the UK manufacturing, Research Policy, Vol. 39 No.6, pp. 762-775. 